\title{
Meta-analysis of the association between preoperative anaemia and mortality after surgery
}

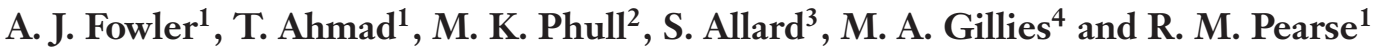 \\ ${ }^{1}$ Barts and the London School of Medicine and Dentistry, Queen Mary University of London, and Departments of ${ }^{2}$ Anaesthesia and ${ }^{3}$ Haematology, \\ Royal London Hospital, Barts Health NHS Trust, London, and ${ }^{4}$ Department of Anaesthesia, Critical Care and Pain Medicine, Royal Infirmary of \\ Edinburgh, Edinburgh, UK \\ Correspondence to: Professor R. M. Pearse, Adult Critical Care Unit, Royal London Hospital, London E1 1BB, UK (e-mail: r.pearse@qmul.ac.uk)
}

\begin{abstract}
Background: Numerous published studies have explored associations between anaemia and adverse outcomes after surgery. However, there are no evidence syntheses describing the impact of preoperative anaemia on postoperative outcomes.

Methods: A systematic review and meta-analysis of observational studies exploring associations between preoperative anaemia and postoperative outcomes was performed. Studies investigating trauma, burns, transplant, paediatric and obstetric populations were excluded. The primary outcome was 30-day or in-hospital mortality. Secondary outcomes were acute kidney injury, stroke and myocardial infarction. Predefined analyses were performed for the cardiac and non-cardiac surgery subgroups. A post hoc analysis was undertaken to evaluate the relationship between anaemia and infection. Data are presented as odds ratios (ORs) with 95 per cent c.i.

Results: From 8973 records, 24 eligible studies including 949445 patients were identified. Some 371594 patients (39.1 per cent) were anaemic. Anaemia was associated with increased mortality (OR 2.90, 2.30 to $3.68 ; I^{2}=97$ per cent; $P<0.001$ ), acute kidney injury (OR $3.75,2.95$ to $4.76 ; I^{2}=60$ per cent; $P<0.001$ ) and infection (OR 1.93, 1.17 to $3 \cdot 18 ; I^{2}=99$ per cent; $\left.P=0.01\right)$. Among cardiac surgical patients, anaemia was associated with stroke (OR $1.28,1.06$ to $1.55 ; I^{2}=0$ per cent; $P=0.009$ ) but not myocardial infarction (OR 1.11, 0.68 to $1.82 ; I^{2}=13$ per cent; $P=0.67$ ). Anaemia was associated with an increased incidence of red cell transfusion (OR 5.04, 4.12 to $6 \cdot 17 ; I^{2}=96$ per cent; $P<0.001$ ). Similar findings were observed in the cardiac and non-cardiac subgroups.

Conclusion: Preoperative anaemia is associated with poor outcomes after surgery, although heterogeneity between studies was significant. It remains unclear whether anaemia is an independent risk factor for poor outcome or simply a marker of underlying chronic disease. However, red cell transfusion is much more frequent amongst anaemic patients.
\end{abstract}

PODCAST
$\begin{array}{r}\text { AVALABLE } \\ \text { ONLINE }\end{array}$

\section{Introduction}

Each year more than 230 million patients undergo surgery worldwide ${ }^{1}$. Estimates of attributable mortality vary from 1 to 4 per cent; however, studies suggest that more than 80 per cent of deaths occur in a subgroup of high-risk surgical patients ${ }^{1-4}$. Successfully treated complications may still be associated with reduced long-term survival ${ }^{3}$. Epidemiological studies suggest that patient co-morbidities, including anaemia, are associated with increased rates of complication and death following surgery ${ }^{2,5}$. Anaemia may be defined either as a reduced number of circulating red blood cells as a percentage of blood volume (haematocrit), or as a decreased concentration of circulating haemoglobin ${ }^{6}$. The prevalence of anaemia among the general population is approximately 20 per cent in Europe ${ }^{7}$, but is as high as 90 per cent amongst some surgical patient populations ${ }^{8,9}$.

Anaemia may be more common within the surgical population for various reasons and can have multiple aetiologies including haematinic deficiencies, in particular iron deficiency, blood loss, or anaemia of chronic disease secondary to malignancy or an inflammatory state. Guidelines on preoperative screening for anaemia may also influence the perceived prevalence ${ }^{10}$. Observational studies suggest an association between anaemia in the perioperative period and postoperative mortality. However, 
it remains uncertain whether anaemia is an independent risk factor for poor postoperative outcome or a marker of the severity of co-morbid disease. It is also unknown whether the treatment of anaemia through allogeneic red cell transfusion is associated with harm or benefit ${ }^{11,12}$. Studies of surgical patients suggest that transfusion of even a small volume of allogeneic red cells is associated with an increase in postoperative mortality ${ }^{13}$.

The concept of patient blood management (PBM) has been introduced to promote best practice in the timely detection and management of preoperative anaemia ${ }^{14}$. The principles of PBM are optimization of the patient's red cell mass, minimization of blood loss during surgery and the appropriate use of transfusion triggers ${ }^{15}$. The clinical effects of various preoperative interventions are currently being investigated in randomized trials including intravenous iron and erythropoietin. However, the most effective methods of treating anaemia in the perioperative period have yet to be defined and further research is needed to address this uncertainty. The association between preoperative anaemia and postoperative outcome has been explored in various studies, but with inconsistent results. To date, there have been no published syntheses of the evidence to summarize the impact of this condition in surgery. A systematic review and meta-analysis of observational studies was therefore performed to examine the associations between preoperative anaemia and clinical outcomes following surgery, and to evaluate the incidence of allogeneic blood transfusion to treat anaemia.

\section{Methods}

The study protocol was published on PROSPERO, the international prospective register of systematic reviews (reference: CRD42014010795; http://www.crd.york. ac.uk/PROSPERO). The search and analysis were performed according to the Preferred Reporting Items for Systematic Reviews and Meta-Analyses (PRISMA) statement ${ }^{16}$.

\section{Search strategy}

MEDLINE, Embase and the Cochrane database of systematic reviews were searched (1946 to present), as well as GreyNet (www.greynet.com), Web of Science (wok.mimas.ac.uk) and citations of included articles. Table 1 shows the search strategy used for the Cochrane Library; this was then translated for different database syntaxes. The full search strategy for each database is shown in Tables $S 1$ and $S 2$ (supporting information).

Search results were limited to observational trials in adult subjects conducted in the past 20 years.
Table 1 Cochrane Library search strategy

$\begin{array}{ll}\# 1 & \text { anemia or } \mathrm{Hb} \text { or haematocrit* or haemoglobin } \\ \# 2 & \text { outcome* or death or mortality } \\ \# 3 & \text { surgery or surgical or operat } \\ \# 4 & \# 1 \text { and \#2 and \#3 }\end{array}$

Non-English-language papers were included. The bibliographies of evaluable studies and other selected papers were searched manually. The literature search was conducted by a literature search specialist.

\section{Study selection criteria}

Duplicates were removed and the remaining records were entered into a database (Mendeley, London, UK). The titles and abstracts of records were then screened to select articles for full-text assessment. Full texts were downloaded, and lead authors contacted if the article was not available. Two authors independently determined suitability for inclusion. Articles were included if: they were observational in design, reported 30-day or in-hospital mortality, incidence of acute kidney injury, stroke or myocardial infarction (using the authors' definitions) in relation to preoperative haemoglobin levels; study subjects were over 16 years of age; and the study had a comparable non-anaemic group. Articles were excluded if study subjects underwent burns, obstetric, trauma or transplant surgery. Studies were assessed for methodological quality using the Newcastle-Ottawa Scale, assigning up to 9 points for selection and comparability of cohorts and assessment of outcome ${ }^{17}$. Studies with a score of less than 6 were excluded. The final article selection was confirmed independently by two authors.

\section{Data extraction}

Data including study characteristics, patient characteristics, definitions of anaemia, patient outcomes and statistical adjustment were extracted using a standard form (Fig. S1, supporting information) and then entered into a database (Excel $^{\circledR}$ 2007; Microsoft, Redmond, Washington, USA). Study authors were contacted where required data were not reported.

\section{Clinical outcomes}

The primary outcome measure was a composite of death within 30 days of surgery or death before hospital discharge. Secondary outcomes were the incidence of acute kidney injury, stroke and myocardial infarction within 30 days of surgery, using the authors' definitions. 


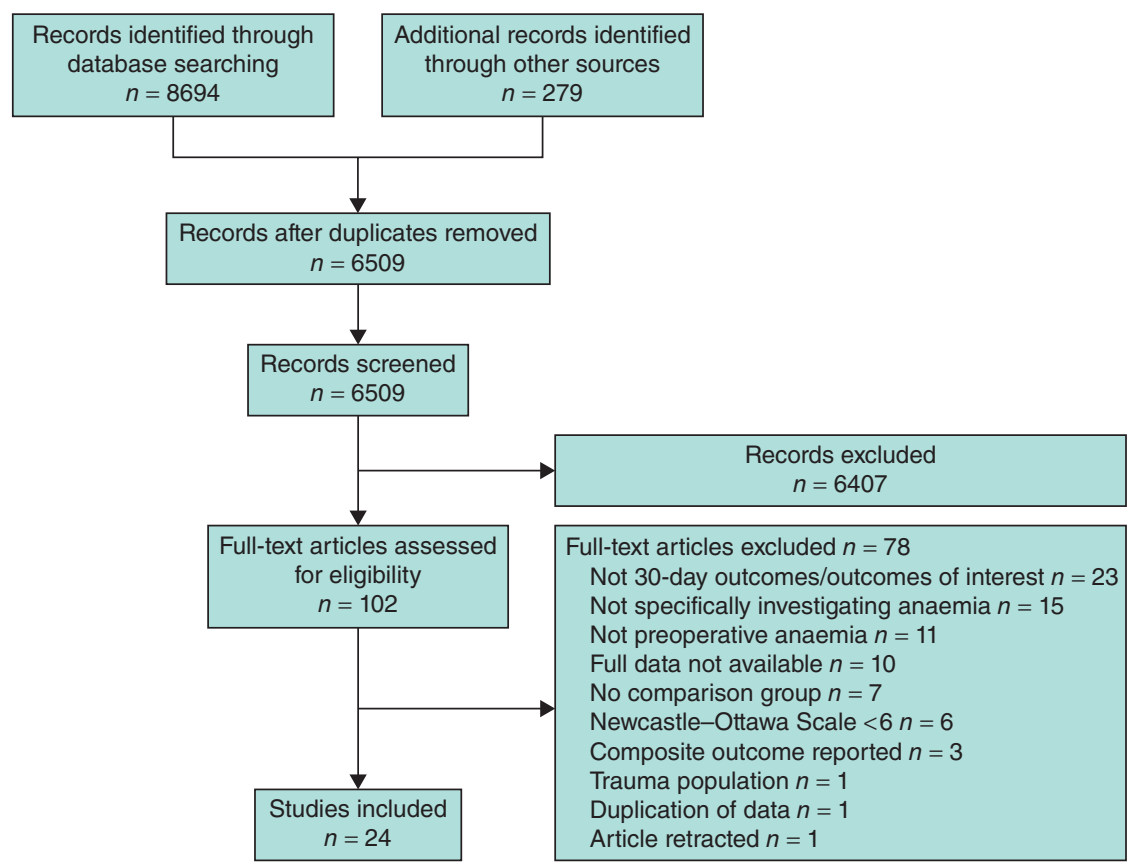

Fig. 1 PRISMA flow diagram of article selection

\section{Statistical analysis}

All statistical analyses were undertaken using Review Manager version 5.3 (The Cochrane Collaboration, The Nordic Cochrane Centre, Copenhagen, Denmark). Studies and their characteristics were first tabulated. Between-study statistical heterogeneity was assessed by $\chi^{2}$ and $I^{2}$ tests, and values of 25,50 and 75 per cent were used to indicate the presence of low, moderate and high between-trial heterogeneity respectively. $P<0 \cdot 100$ was considered to denote the statistical significance of heterogeneity. A funnel plot was constructed for the primary outcome and assessed visually to establish the risk of publication bias. For all analyses performed, if no significant heterogeneity was noted, a fixed-effect model analysis using the Mantel-Haenszel method was used. If significant heterogeneity was noted, a random-effects model analysis using the DerSimonian-Laird method was employed. Predefined subgroup analyses were undertaken to explore the effect of anaemia in patients undergoing cardiac and non-cardiac surgery. A sensitivity analysis using a random-effects model was performed including only studies that had applied the World Health Organization (WHO) definition of anaemia (less than $12 \mathrm{~g} / \mathrm{dl}$ for female and less than $13 \mathrm{~g} / \mathrm{dl}$ for male patients) ${ }^{18}$. A post hoc analysis was undertaken to explore the relationship between anaemia and postoperative infection. Forest plots were then created to summarize the models. Findings are presented as odds ratios (ORs) with 95 per cent c.i.

\section{Results}

\section{Study selection}

A total of 8694 records were identified from the electronic search strategy, with a further 275 records through grey literature searches, and four records by hand search. After removal of duplicates, 6509 records remained. The full texts of manuscripts reporting 102 studies were retrieved, of which 24 met the inclusion criteria (Fig. 1).

\section{Characteristics of included studies}

Characteristics of the included studies are summarized in Table $2^{5,19-41}$. A total of 949445 patients were included, and all 24 studies reported the primary outcome of 30-day or in-hospital mortality. Eight articles reported acute kidney injury. Stroke was reported in six studies, and five reported myocardial infarction (Table $S 3$, supporting information). However, stroke and myocardial infarction were reported as an outcome only in studies of patients undergoing cardiac surgery (Table 2). A haemoglobin definition was used in 17 studies $5,19,20,22-26,28-31,33,37-39,41$, a haematocrit definition in six studies ${ }^{27,32,34-36,40}$, and both definitions were used in one study ${ }^{21}$. Definitions of anaemia 
Table 2 Characteristics of included studies

\begin{tabular}{|c|c|c|c|c|c|c|c|c|c|c|c|}
\hline \multirow[b]{2}{*}{ Reference } & \multirow[b]{2}{*}{$\begin{array}{l}\text { Study } \\
\text { design }\end{array}$} & \multirow[b]{2}{*}{ Surgery } & \multirow[b]{2}{*}{$\begin{array}{l}\text { No. with } \\
\text { anaemia }\end{array}$} & \multirow[b]{2}{*}{$\begin{array}{l}\text { No. without } \\
\text { anaemia }\end{array}$} & \multirow[b]{2}{*}{$\begin{array}{c}\text { Definition of } \\
\text { anaemia }(\mathrm{g} / \mathrm{dl})^{\star}\end{array}$} & \multicolumn{4}{|c|}{ Outcomes reported } & \multirow{2}{*}{$\begin{array}{l}\text { PRBC } \\
\text { transfusion } \\
\text { reported }\end{array}$} & \multirow[b]{2}{*}{ NOS score } \\
\hline & & & & & & Mortality & AKI & Stroke & $\mathrm{Ml}$ & & \\
\hline \multirow[t]{2}{*}{5} & PC & Non-cardiac & 11295 & 27439 & $<13(\mathrm{M})$ & Yes & No & No & No & No & 9 \\
\hline & & & & & $<12$ (F) & & & & & & \\
\hline \multirow[t]{2}{*}{19} & PC & Non-cardiac & 3047 & 4632 & $<13(\mathrm{M})$ & Yes & No & No & No & Yes & 9 \\
\hline & & & & & $<12(\mathrm{~F})$ & & & & & & \\
\hline 20 & DB & Cardiac & 6143 & 30196 & $<12$ & Yes & Yes & Yes & No & No & 9 \\
\hline 21 & $\mathrm{RC}$ & Cardiac & 185 & 3126 & $<11$ & Yes & Yes & Yes & Yes & Yes & 6 \\
\hline 22 & $\mathrm{RC}$ & Cardiac & 42 & 159 & $<12$ & Yes & Yes & Yes & Yes & No & 8 \\
\hline \multirow[t]{2}{*}{23} & PC & Cardiac & 320 & 727 & $<13(\mathrm{M})$ & Yes & Yes & Yes & No & Yes & 7 \\
\hline & & & & & $<12(\mathrm{~F})$ & & & & & & \\
\hline \multirow[t]{2}{*}{24} & PC & Orthopaedic & 185 & 158 & $<13(\mathrm{M})$ & Yes & No & No & No & No & 6 \\
\hline & & & & & $<12(\mathrm{~F})$ & & & & & & \\
\hline \multirow[t]{2}{*}{25} & $\mathrm{RC}$ & Orthopaedic & 2991 & 12231 & $<13(\mathrm{M})$ & Yes & No & No & No & Yes & 6 \\
\hline & & & & & $<12(\mathrm{~F})$ & & & & & & \\
\hline \multirow[t]{2}{*}{26} & PC & Orthopaedic & 180 & 215 & $<13(\mathrm{M})$ & Yes & No & No & No & Yes & 9 \\
\hline & & & & & $<12(\mathrm{~F})$ & & & & & & \\
\hline 27 & DB & Vascular & 15272 & 16585 & $<39 \% \dagger$ & Yes & No & No & No & No & 9 \\
\hline \multirow[t]{2}{*}{28} & PC & Cardiac & 1463 & 1225 & $<13(\mathrm{M})$ & Yes & No & No & No & Yes & 6 \\
\hline & & & & & $<12(\mathrm{~F})$ & & & & & & \\
\hline \multirow[t]{2}{*}{29} & $\mathrm{RC}$ & $\mathrm{Gl}$ & 125 & 463 & $<13(\mathrm{M})$ & Yes & No & No & No & No & 6 \\
\hline & & & & & $<12(\mathrm{~F})$ & & & & & & \\
\hline \multirow[t]{2}{*}{30} & $\mathrm{RC}$ & $\mathrm{Gl}$ & 197 & 216 & $<13(\mathrm{M})$ & Yes & No & No & No & Yes & 6 \\
\hline & & & & & $<12(\mathrm{~F})$ & & & & & & \\
\hline \multirow[t]{2}{*}{31} & $\mathrm{RC}$ & Cardiac & 210 & 366 & $<13(\mathrm{M})$ & Yes & Yes & Yes & Yes & Yes & 7 \\
\hline & & & & & $<12(\mathrm{~F})$ & & & & & & \\
\hline \multirow[t]{2}{*}{32} & DB & Non-cardiac & 69229 & 158196 & $<39 \% \dagger(\mathrm{M})$ & Yes & Yes & No & No & Yes & 9 \\
\hline & & & & & $<36 \% \dagger(\mathrm{F})$ & & & & & & \\
\hline \multirow[t]{2}{*}{33} & $\mathrm{RC}$ & Vascular & 193 & 167 & $<14(\mathrm{M})$ & Yes & No & No & No & No & 7 \\
\hline & & & & & $<12(\mathrm{~F})$ & & & & & & \\
\hline 34 & $\mathrm{RC} \ddagger$ & Cardiac & 401 & 401 & $<30 \% \dagger$ & Yes & Yes & Yes & Yes & Yes & 7 \\
\hline \multirow[t]{2}{*}{35} & $\mathrm{DB}:$ & Non-cardiac & 119298 & 119298 & $<39 \% \dagger(\mathrm{M})$ & Yes & No & No & No & No & 9 \\
\hline & & & & & $<36 \% \dagger(\mathrm{F})$ & & & & & & \\
\hline 36 & DB & Spinal & 5879 & 18594 & $<38 \% \dagger$ & Yes & No & No & No & Yes & 8 \\
\hline 37 & $\mathrm{RC}$ & Cardiac & 650 & 3782 & $<12$ & Yes & No & No & No & $\begin{array}{l}\text { Transfused } \\
\text { patients } \\
\text { excluded }\end{array}$ & 7 \\
\hline 38 & $\mathrm{RC}$ & Cardiac & 351 & 1385 & $<13(\mathrm{M})$ & Yes & No & No & No & No & 6 \\
\hline & & & & & $<12(\mathrm{~F})$ & & & & & & \\
\hline 39 & $\mathrm{RC}$ & Orthopaedic & 536 & 726 & $<13(\mathrm{M})$ & Yes & No & No & No & Yes & 6 \\
\hline & & & & & $<12(\mathrm{~F})$ & & & & & & \\
\hline 40 & DB & Non-cardiac & 132970 & 177341 & $<39 \% \dagger$ & Yes & No & No & No & No & 9 \\
\hline 41 & $\mathrm{RC}$ & Cardiac & 432 & 223 & $<13(\mathrm{M})$ & Yes & Yes & No & Yes & Yes & 9 \\
\hline & & & & & $<12(\mathrm{~F})$ & & & & & & \\
\hline
\end{tabular}

All outcomes are reported at 30 days or in hospital. *Haemoglobin level below which patients were considered anaemic; thaematocrit definition was used and is presented as a percentage. \$A propensity-matched cohort was used in this analysis. AKI, acute kidney injury; MI, myocardial infarction; PRBC, packed red blood cell; NOS, Newcastle-Ottawa Scale; PC, prospective cohort; DB, national or international database retrospective review; RC, retrospective cohort; GI, gastrointestinal.

ranged from a haemoglobin concentration of 11 to $12 \mathrm{~g} / \mathrm{dl}$ or a haematocrit of 30-39 per cent for female patients, and from 11 to $14 \mathrm{~g} / \mathrm{dl}$ or $30-39$ per cent respectively for male patients. Eight studies were of multicentre design. Nine studies (including 855031 patients) were performed in the USA, and 11 reported the timing of haemoglobin measurement, which varied from time of anaesthesia induction to 6 weeks before surgery.

\section{Frequency of anaemia and blood transfusion}

In total, 371594 of the 949445 patients were anaemic as defined by the authors of included studies $(39 \cdot 1$ per cent). When restricted to the 13 studies reporting the WHO definition, 21322 (29.9 per cent) of 71338 patients were anaemic. Thirteen studies reported the incidence of allogeneic red cell transfusion (Table 2), which was 


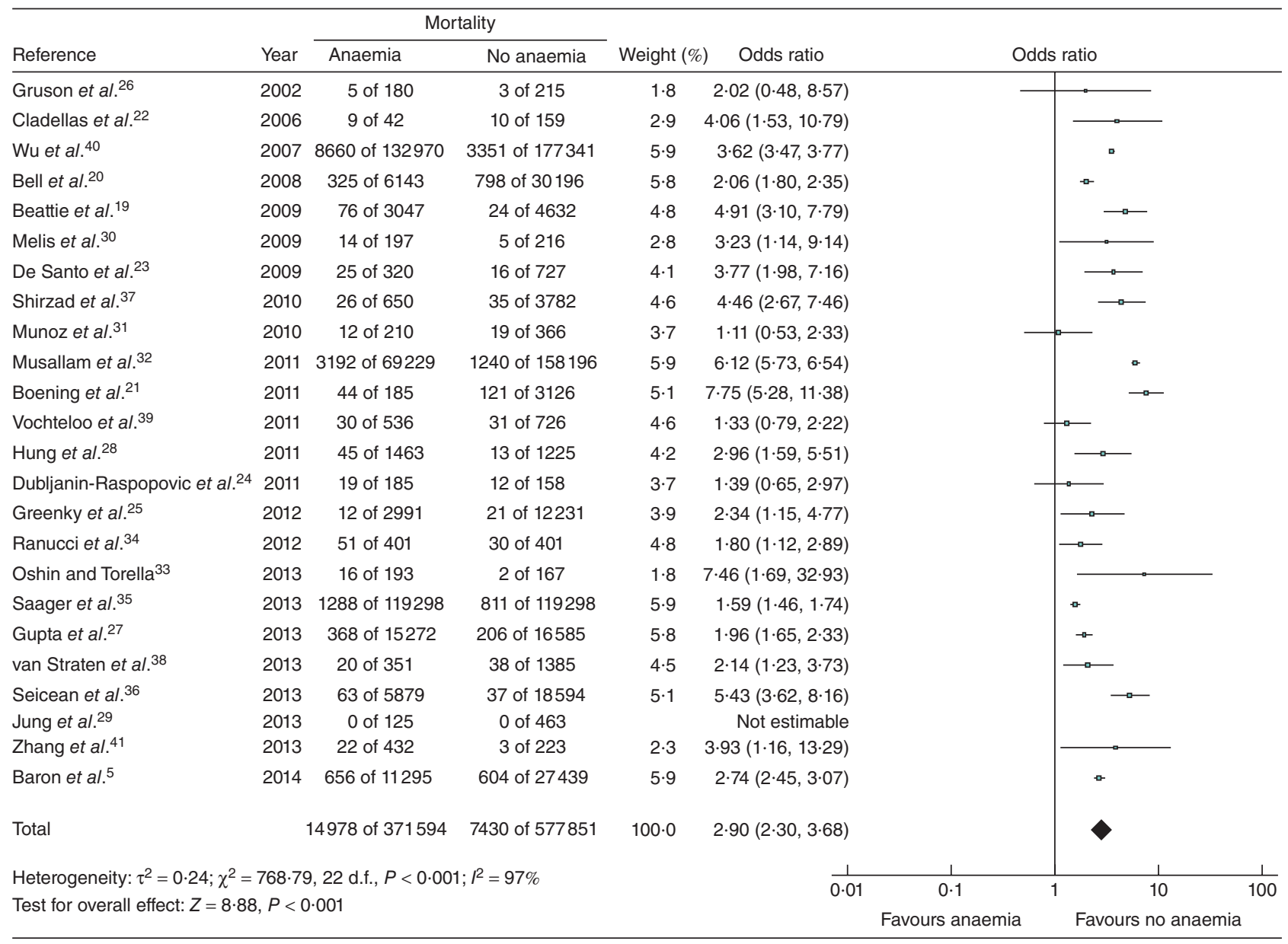

Fig. 2 Forest plot showing composite outcome of 30-day or in-hospital mortality after surgery, according to author-defined anaemia. Sizes of markers indicate weight for each study according to sample size. A Mantel-Haenszel random-effects model was used for meta-analysis. Odds ratios are shown with 95 per cent c.i.

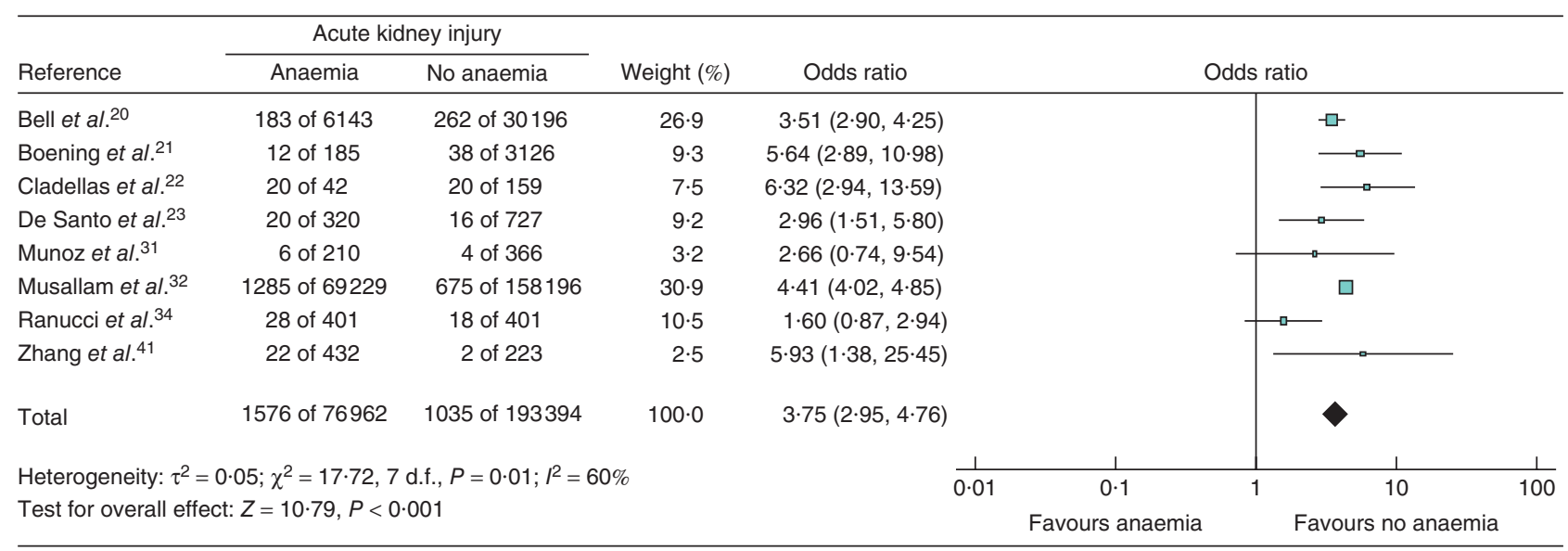

Fig. 3 Forest plot of acute kidney injury, according to author-defined anaemia. Sizes of markers indicate weight for each study according to sample size. A Mantel-Haenszel random-effects model was used for meta-analysis. Odds ratios are shown with 95 per cent c.i. 


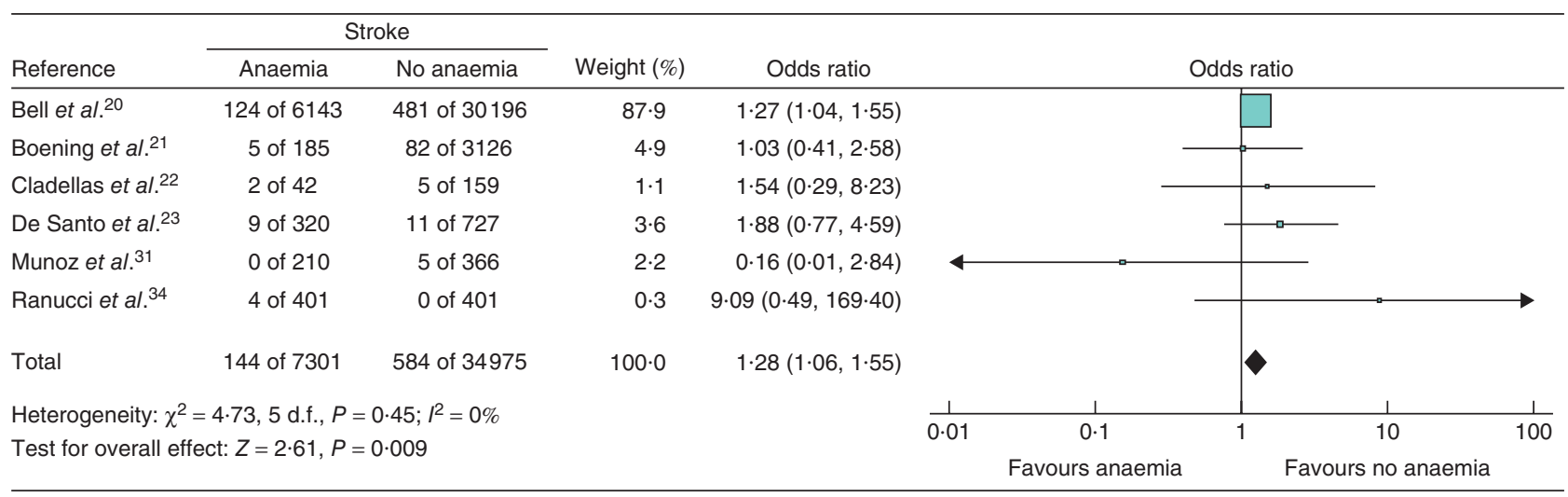

Fig. 4 Forest plot of stroke, according to author-defined anaemia. Sizes of markers indicate weight for each study according to sample size. A Mantel-Haenszel fixed-effect model was used for meta-analysis. Odds ratios are shown with 95 per cent c.i.

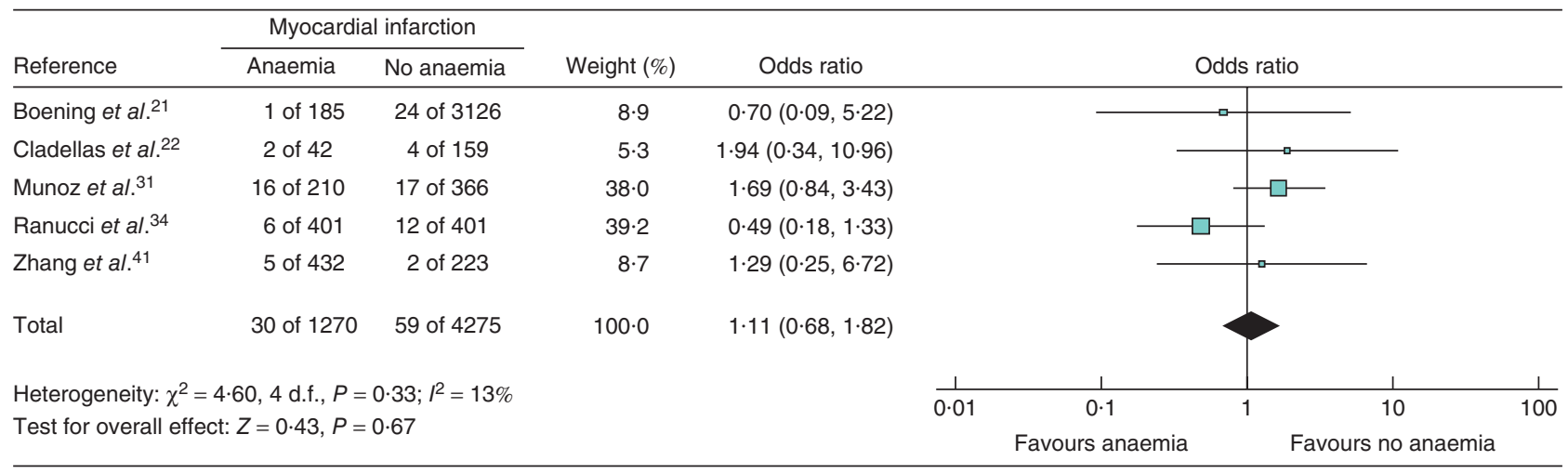

Fig. 5 Forest plot of myocardial infarction, according to author-defined anaemia. Sizes of markers indicate weight for each study according to sample size. A Mantel-Haenszel fixed-effect model was used for meta-analysis. Odds ratios are shown with 95 per cent c.i.

more frequent amongst anaemic patients (15 804 (18.5 per cent) in anaemic groups versus 9539 ( 4.7 per cent) in non-anaemic groups; OR $5 \cdot 04,4 \cdot 12$ to $6 \cdot 17 ; I^{2}=96$ per cent; $P<0.001$ ) (Fig. S2, supporting information). Patients who received an allogeneic red cell transfusion were excluded from one study ${ }^{37}$, and one article reported allogeneic red cell transfusion rates only for anaemic patients ${ }^{33}$. Statistical adjustment was carried out in all included studies, but the method used and variables included in models were too varied to allow separate analysis. The funnel plot was symmetrical, indicating that publication bias is unlikely (Fig. S3, supporting information).

\section{Primary outcome}

\section{In-hospital or 30-day mortality}

Mortality was reported in all included studies, 12 as 30-day mortality, eight as in-hospital mortality, and in four studies a composite of both outcomes was presented. A total of 22408 patients ( 2.4 per cent) died within 30 days after surgery or before hospital discharge. Anaemic patients died more frequently (OR 2.90, 2.30 to $3.68 ; I^{2}=97$ per cent; $P<0.001$ ) (Fig. 2). Between-study heterogeneity was high, possibly owing to the very different populations and definitions used in included studies, and a random-effects model was therefore used. Fourteen reports, including 890605 patients, identified anaemia as an independent risk factor for mortality. Two articles did not report multivariable adjustment, and eight articles (including 58184 patients) did not identify anaemia as an independent risk factor for mortality.

\section{Secondary outcomes}

\section{Acute kidney injury}

Eight studies including 270356 patients reported postoperative acute kidney injury as an outcome measure (Table S3, supporting information), seven of which were confined to patients undergoing cardiac surgery (Table 2). Anaemia was associated with an increased incidence of 


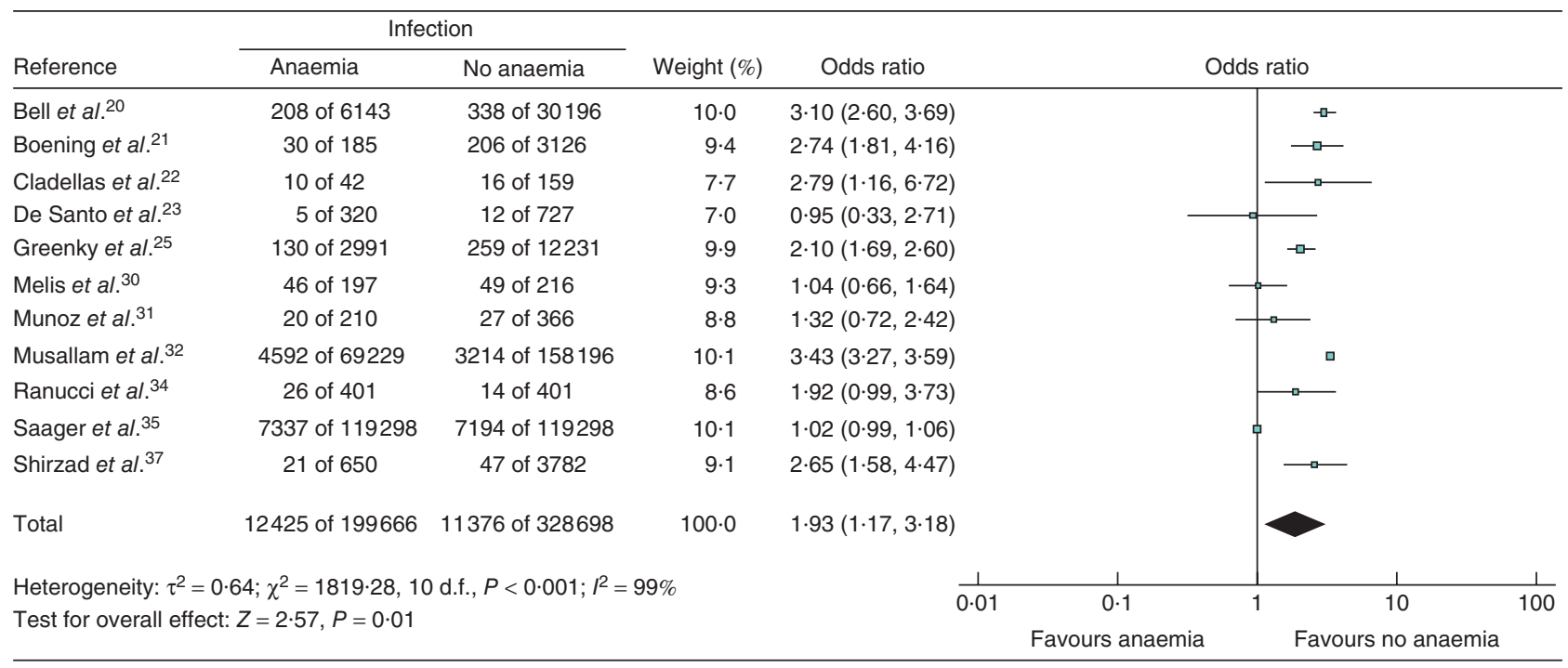

Fig. 6 Forest plot of risk of infection in anaemic versus non-anaemic patients. Sizes of markers indicate weight for each study according to sample size. A Mantel-Haenszel random-effects model was used for meta-analysis. Odds ratios are shown with 95 per cent c.i.

postoperative acute kidney injury (OR 3.75, 2.95 to 4.76; $I^{2}=60$ per cent; $P<0 \cdot 001$ ) (Fig. 3). Between-study heterogeneity was moderate and a random-effects model was used.

\section{Stroke}

Six studies including 42276 patients reported postoperative stroke as an outcome measure (Table $S 3$, supporting information). All of these studies were confined to patients having cardiac surgery (Table 2). Anaemia was associated with an increased risk of stroke in these studies (OR 1.28, 1.06 to $1.55 ; I^{2}=0$ per cent; $P=0.009$ ) (Fig. 4). There was no between-study heterogeneity and a fixed-effect model was used.

\section{Myocardial infarction}

Five studies including 5545 patients reported postoperative myocardial infarction as an outcome measure (Table S3, supporting information). All of these studies were confined to patients undergoing cardiac surgery (Table 2). There was no significant difference in the incidence of myocardial infarction between anaemic and non-anaemic patients (OR $1 \cdot 11,0.68$ to $1 \cdot 82 ; I^{2}=13$ per cent; $P=0.67$ ) (Fig. 5). There was low between-study heterogeneity and a fixed-effect model was used.

\section{Subgroup analyses}

Non-cardiac surgery

Fourteen studies were identified including 897658 non-cardiac surgical patients of whom 361397 (40.3 per cent) were anaemic. These studies described various surgical specialty groups including vascular, orthopaedic, spinal and upper gastrointestinal surgery. Anaemia was associated with an increased risk of death in non-cardiac surgical patients $\left(\mathrm{OR} 2 \cdot 87,2 \cdot 10\right.$ to $3 \cdot 93 ; I^{2}=98$ per cent; $P<0.001)$ (Fig. S4, supporting information). There was high between-study heterogeneity and a random-effects model was used.

\section{Cardiac surgery}

Ten studies were identified including 51787 cardiac surgical patients, of whom 10197 (19.7 per cent) were anaemic. Anaemia was associated with an increased risk of death for patients undergoing cardiac surgery (OR 2.98, 2.02 to $4.38 ; I^{2}=84$ per cent; $P<0 \cdot 001$ ) (Fig. $S 4$, supporting information).

\section{Sensitivity analysis}

\section{World Health Organization definition of anaemia}

The WHO definition of anaemia was employed in 13 studies including 71338 patients, of whom 21332 (29.9 per cent) were anaemic. When the analysis was restricted to these studies, the association between anaemia and postoperative mortality remained (OR 2.46, 1.91 to $3 \cdot 17 ; I^{2}=56$ per cent; $P<0.001$ ) (Fig. S5, supporting information). Between-study heterogeneity was moderately reduced, probably because of the uniform definitions dividing the study populations, and a random-effects model was used. 


\section{Post hoc analysis}

\section{Postoperative infection}

During review of the literature, 11 studies were identified that included data describing postoperative infection, seven in the setting of cardiac surgery and four in non-cardiac surgery. An additional post hoc analysis using a random-effects model to evaluate the relationship between preoperative anaemia and postoperative infection was therefore performed. Some 23801 (4.5 per cent) of 528364 patients developed an infection after surgery. Anaemia was associated with an increased incidence of infection (OR 1.93, 1.17 to $3.18 ; I^{2}=99$ per cent; $P=0.01$ ) (Fig. 6). There was high between-study heterogeneity, probably owing to the variety of included infections, and a random-effects model was used.

\section{Discussion}

The principal finding of this analysis is that preoperative anaemia is associated with increased short-term mortality after surgery. This association was also present when cardiac and non-cardiac surgery subgroups were analysed separately, and in studies that employed the WHO definition of anaemia. Preoperative anaemia is also associated with an increased risk of acute kidney injury and infection after surgery. Amongst cardiac surgical patients, preoperative anaemia is associated with stroke but not myocardial infarction, perhaps reflecting improved coronary artery perfusion after surgery. These observations do not confirm a causal relationship, but it is important to note that the diagnosis of anaemia appears to alter clinical practice because allogeneic red cell transfusion is more frequent amongst anaemic patients. Statistical heterogeneity was very high for a number of analyses, probably owing to the very different populations and definitions of anaemia used in included studies. Caution is therefore required in interpretation of these findings.

The findings of this systematic review of 24 studies are consistent with those of the component studies, which either suggest that preoperative anaemia is associated with adverse outcomes following surgery, or show no difference in these outcomes. The present findings are also consistent with reports in other patient groups suggesting that anaemia is associated with poor outcome $e^{8,9}$. It is interesting to note that the association between anaemia and mortality was stronger than that with morbidity. This partly reflects the fact that fewer reports provide data describing morbidity outcomes, but may also be explained by inconsistent reporting of complications within and between studies, and the high levels of heterogeneity associated with the present mortality findings. The stroke outcome data should be interpreted with caution as 86.0 per cent of patients in this analysis were contributed by a single study ${ }^{20}$ of patients undergoing coronary artery bypass.

The absence of any association between myocardial infarction and anaemia is surprising, given first principles of physiology regarding the balance of myocardial oxygen supply and demand. This may relate to the fact that myocardial infarction was reported as a separate outcome in only a few studies contributing 5545 cardiac surgical patients, compared with 42276 patients with data describing the outcome of stroke and 270356 describing acute kidney injury.

Perhaps unsurprisingly, allogeneic red cell transfusion occurred at a higher rate amongst anaemic than nonanaemic patients. Both anaemia and its treatment by allogeneic red cell transfusion have been associated with increased mortality and morbidity, and it remains unclear whether correcting preoperative anaemia can improve outcomes ${ }^{14}$. Investigators are exploring the value of various preoperative treatments for anaemia, including intravenous iron and erythropoietin. However, the evidence base for this area of clinical practice remains limited. Other aspects of patient blood management, such as minimizing perioperative blood loss through the use of tranexamic acid, are also being explored ${ }^{42}$. Anaemic patients are more likely to develop an infection following surgery, perhaps reflecting the immunosuppressant effects of allogeneic red cell transfusion, as well as the increased incidence of co-morbid disease in the anaemic population ${ }^{43}$.

The present findings emphasize the importance of anaemia and PBM, which has been promoted by the WHO, with initiatives under way in many countries. In the UK, the National Health Service has issued guidance for this area of practice, and a formal National Institute for Health and Care Excellence guideline is currently in draft. It was not possible to account for the potential confounding effect of co-morbid disease, and it remains unclear whether anaemia is the cause of poor outcome after surgery or a marker of increased risk. The data sets available to many of the included studies probably included only those patients who required preoperative haemoglobin estimation. Some element of reporting bias seems likely, and the proportion of anaemic patients may be overestimated.

The strength of this study is that it was conducted according to a robust, prospectively written and published analysis plan by a multidisciplinary group, with experience in meta-analyses in perioperative medicine and haematology. Studies were assessed rigorously for methodological quality, and only those of sufficient quality were included in the analysis. However, this analysis has a number of limitations, 
the principal one being the high level of statistical and clinical heterogeneity in the findings. This heterogeneity likely exists because of the variety of populations studied and the different definitions used by included studies. Preoperative timing of haemoglobin or haematocrit reporting was reported infrequently, preventing any adjustment for this source of bias. A number of studies reported haematocrit, creating additional heterogeneity in the available data. It is also possible that all eligible papers were not located by the electronic search strategy. It was not possible to adjust for the effect of allogeneic red cell transfusion, owing to the largely unavailable data describing the number of red cell transfusions received per patient. This limited the ability to determine the independent effect of anaemia on outcome. Where risk adjustment was reported, the technique used varied widely. Unmeasured confounding and selection bias are often present in observational studies, and it remains possible that the use of observational data with such bias may produce spurious results with an apparently high degree of precision ${ }^{44}$. The high level of between-study heterogeneity observed may place the present analysis at risk of this. Moreover, cardiac surgery is over-represented within this cohort. The majority of component studies were single-centre in design, and five component studies were derived from the same database (National Surgical Quality Improvement Project, USA). This may have resulted in overlap of included patients; however, a sensitivity analysis was performed excluding all but the largest of these studies, and the findings remained unchanged $^{40}$.

Preoperative anaemia is associated with increased short-term mortality after surgery, as well as an increased incidence of stroke, acute kidney injury and infection. These results should be interpreted with care given the high levels of heterogeneity between studies. Although these observations will, at least partially, reflect the severity of co-morbid disease among included patients, allogeneic red cell transfusion is also more common in the presence of anaemia. The current evidence base for allogeneic red cell transfusion in surgical patients is limited. There is, therefore, a need for large, well designed, randomized trials with a low risk of bias to confirm the optimal strategies for the treatment of anaemia in the perioperative period.

\section{Acknowledgements}

The authors thank $M$. Ahmed for assistance with the design and conduct of the literature search.

R.M.P. has received equipment loans from LiDCO Ltd, an unrestricted research grant from Nestlé Health Science, and fees for consultancy and/or speaking from Edwards Lifesciences, Nestlé and Massimo Inc.

Disclosure: The authors declare no other conflict of interest.

\section{References}

1 Weiser TG, Regenbogen SE, Thompson KD, Haynes AB, Lipsitz SR, Berry WR et al. An estimation of the global volume of surgery: a modelling strategy based on available data. Lancet 2008; 372: 139-144.

2 Pearse RM, Moreno RP, Bauer P, Pelosi P, Metnitz P, Spies $\mathrm{C}$ et al. Mortality after surgery in Europe: a 7 day cohort study. Lancet 2012; 380: 1059-1065.

3 Khuri SF, Henderson WG, DePalma RG, Mosca C, Healey NA, Kumbhani DJ. Determinants of long-term survival after major surgery and the adverse effect of postoperative complications. Ann Surg 2005; 242: 326-343.

4 Pearse RM, Harrison DA, James P, Watson D, Hinds C, Rhodes A et al. Identification and characterisation of the high-risk surgical population in the United Kingdom. Crit Care 2006; 10: R81.

5 Baron DM, Hochrieser H, Posch M, Metnitz B, Rhodes A, Moreno RP et al. Preoperative anaemia is associated with poor clinical outcome in non-cardiac surgery patients. $\operatorname{Br} \mathcal{F}$ Anaesth 2014; 113: 416-423.

6 Beutler E, Waalen J. The definition of anemia: what is the lower limit of normal of the blood hemoglobin concentration? Blood 2006; 107: 1747-1750.

7 de Benoist B, McLean E, Egli I, Cogswell M (eds). WHO Global Database on Anaemia. World Health Organization: Atlanta, 2005.

8 Knight K, Wade S, Balducci L. Prevalence and outcomes of anemia in cancer: a systematic review of the literature. $A m \mathcal{F}$ Med. 2004; 116(Suppl): 11S-26S.

9 Beghé C, Wilson A, Ershler WB. Prevalence and outcomes of anemia in geriatrics: a systematic review of the literature. Am 7 Med 2004; 116(Suppl): 3S-10S.

10 Reeves B, Langham J, Phillips N, Al E. Preoperative Tests: The Use of Routine Preoperative Tests for Elective Surgery. National Institute for Health and Care Excellence: London, 2003.

11 Williamson LM, Love EM. Reporting serious hazards of transfusion: the SHOT program. Transfus Med Rev 1998; 12: $28-35$.

12 Shander A, Javidroozi M, Ozawa S, Hare GMT. What is really dangerous: anaemia or transfusion? Br $\mathcal{F}$ Anaesth 2011; 107(Suppl): i41-i59.

13 Ferraris VA, Davenport DL, Saha SP, Austin PC, Zwischenberger JB. Surgical outcomes and transfusion of minimal amounts of blood in the operating room. Arch Surg 2012; 147: 49-55.

14 Shander A, Van Aken H, Colomina MJ, Gombotz H, Hofmann A, Krauspe R et al. Patient blood management in Europe. Br 7 Anaesth 2012; 109: 55-68.

15 Goodnough L, Shander A. Patient blood management. Anesthesiology 2012; 116: 1367-1376. 
16 Moher D, Liberati A, Tetzlaff J, Altman DG. Preferred reporting items for systematic reviews and meta-analyses: the PRISMA statement. PLoS Med 2009; 6: e1000097.

17 Stang A. Critical evaluation of the Newcastle-Ottawa Scale for the assessment of the quality of nonrandomized studies in meta-analyses. Eur 7 Epidemiol 2010; 25: 603-605.

18 World Health Organization (WHO). Haemoglobin concentrations for the diagnosis of anaemia and assessment of severity. In Vitamin and Mineral Nutrition Information System. WHO: Geneva, 2011; 1-6.

19 Beattie WS, Karkouti K, Wijeysundera DN, Tait G. Risk associated with preoperative anemia in noncardiac surgery: a single-center cohort study. Anesthesiology 2009; 110: 574-581.

20 Bell ML, Grunwald GK, Baltz JH, McDonald GO, Grover FL, Shroyer AL. Does preoperative hemoglobin independently predict short-term outcomes after coronary artery bypass graft surgery? Ann Thorac Surg 2008; 86: 1415-1423.

21 Boening A, Boedeker RH, Scheibelhut C, Rietzschel J, Roth $\mathrm{P}$, Schonburg M. Anemia before coronary artery bypass surgery as additional risk factor increases the perioperative risk. Ann Thorac Surg 2011; 92: 805-810.

22 Cladellas M, Bruguera J, Comin J, Vila J, De Jamie E, Marti $\mathrm{J}$ et al. Is pre-operative anaemia a risk marker for in-hospital mortality and morbidity after valve replacement? Eur Heart 7 2006; 27: 1093-1099.

23 De Santo L, Romano G, Della Corte A, de Simone V, Grimaldi F, Cotrufo M et al. Preoperative anemia in patients undergoing coronary artery bypass grafting predicts acute kidney injury. 7 Thorac Cardiovasc Surg 2009; 138: 965-970.

24 Dubljanin-Raspopovic E, Markovic-Denic L, Nikolic D, Tulic G, Kadija M, Bumbasirevic M et al. Is anemia at admission related to short-term outcomes of elderly hip fracture patients? Cent Eur 7 Med 2011; 6: 483-489.

25 Greenky M, Gandhi K, Pulido L, Restrepo C, Parvizi J. Preoperative anemia in total joint arthroplasty: is it associated with periprosthetic joint infection? Clin Orthop Relat Res 2012; 470: 2695-2701.

26 Gruson KI, Aharonoff GB, Egol KA, Zuckerman JD, Koval KJ. The relationship between admission hemoglobin level and outcome after hip fracture. 7 Orthop Trauma 2002; 16: $39-44$.

27 Gupta PK, Sundaram A, Mactaggart JN, Johanning JM, Gupta H, Fang X et al. Preoperative anemia is an independent predictor of postoperative mortality and adverse cardiac events in elderly patients undergoing elective vascular operations. Ann Surg 2013; 258: 1096-1102.

28 Hung M, Besser M, Sharples LD, Nair SK, Klein AA. The prevalence and association with transfusion, intensive care unit stay and mortality of pre-operative anaemia in a cohort of cardiac surgery patients. Anaesthesia 2011; 66: 812-818.

29 Jung DH, Lee HJ, Han DS, Suh YS, Kong SH, Lee KU et al. Impact of perioperative hemoglobin levels on postoperative outcomes in gastric cancer surgery. Gastric Cancer 2013; 16: 377-382.
30 Melis M, McLoughlin JM, Dean EM, Siegel EM, Weber JM, Shah N et al. Correlations between neoadjuvant treatment, anemia, and perioperative complications in patients undergoing esophagectomy for cancer. 7 Surg Res 2009; 153: 114-120.

31 Munoz M, Ariza D, Gomez-Ramirez S, Hernandez P, Garcia-Erce JA, Leal-Noval SR. Preoperative anemia in elective cardiac surgery: prevalence, risk factors, and influence on postoperative outcome. Transfus Altern Transfus Med 2010; 11: 47-56.

32 Musallam KM, Tamim HM, Richards T, Spahn DR, Rosendaal FR, Habbal A et al. Preoperative anaemia and postoperative outcomes in non-cardiac surgery: a retrospective cohort study. Lancet 2011; 378: 1396-1407.

33 Oshin O, Torella F. Low hemoglobin concentration is associated with poor outcome after peripheral arterial surgery. Vasc Endovasc Surg 2013; 47: 449-453.

34 Ranucci M, Di Dedda U, Castelvecchio S, Menicanti L, Frigiola A, Pelissero G et al. Impact of preoperative anemia on outcome in adult cardiac surgery: a propensity-matched analysis. Ann Thorac Surg 2012; 94: 1134-1141.

35 Saager L, Turan A, Reynolds LF, Dalton JE, Mascha EJ, Kurz A. The association between preoperative anemia and 30-day mortality and morbidity in noncardiac surgical patients. Anesth Analg 2013; 117: 909-915.

36 Seicean A, Seicean S, Alan N, Schiltz NK, Rosenbaum BP, Jones PK et al. Preoperative anemia and perioperative outcomes in patients who undergo elective spine surgery. Spine (Phila Pa 1976) 2013; 38: 1331-1341.

37 Shirzad M, Karimi A, Dowlatshahi S, Ahmadi SH, Davoodi S, Marzban M etal. Preoperative anemia associated in-hospital mortality and morbidity in isolated coronary artery bypass graft surgery. Cent Eur 7 Med 2010; 5: 308-314.

38 van Straten AHM, Külcü K, Özdemir HI, Elenbaas TW, Soliman Hamad MA. Preoperative hemoglobin level as a predictor of mortality after aortic valve replacement. 7 Cardiothorac Vasc Anesth 2013; 27: 716-722.

39 Vochteloo AJ, Borger van der Burg BL, Mertens B, Niggebrugge AH, de Vries MR, Tuinebreijer WE et al. Outcome in hip fracture patients related to anemia at admission and allogeneic blood transfusion: an analysis of 1262 surgically treated patients. BMC Musculoskelet Disord 2011; 12: 262.

40 Wu WC, Schifftner TL, Henderson WG, Eaton CB, Poses RM, Uttley G et al. Preoperative hematocrit levels and postoperative outcomes in older patients undergoing noncardiac surgery. 7AMA 2007; 297: 2481-2488.

41 Zhang L, Hiebert B, Zarychanski R, Arora RC, Cardiovascular Health Research in Manitoba (CHaRM) Investigator Group. Preoperative anemia does not increase the risks of early surgical revascularization after myocardial infarction. Ann Thorac Surg 2013; 95: 542-547.

42 Ker K, Edwards P, Perel P, Shakur H, Roberts I. Effect of tranexamic acid on surgical bleeding: systematic review and cumulative meta-analysis. BM7 2012; 344: e3054-e3054. 
43 Rohde JM, Dimcheff DE, Blumberg N, Saint S, Langa KM, Kuhn L et al. Health care-associated infection after red blood cell transfusion. FAMA 2014; 311: 1317.
44 Egger M, Schneider M, Davey Smith G. Spurious precision? Meta-analysis of observational studies. BMF 1998; 316: 140-144.

\section{Supporting information}

Additional supporting information may be found in the online version of this article:

Table S1 MEDLINE search strategy (Word document)

Table S2 Embase search strategy (Word document)

Table S3 Summary of reported outcomes and characteristics (Word document)

Fig. S1 Form used to extract data from identified studies (Word document)

Fig. S2 Forest plot showing risk of transfusion in anaemic patients versus non-anaemic patients (Word document)

Fig. S3 Funnel plot for the primary outcome of this analysis (Word document)

Fig. S4 Forest plot showing composite outcome of 30-day or in-hospital mortality, according to author-defined anaemia and surgical subgroup (Word document)

Fig. S5 Forest plot showing composite outcome of 30-day or in-hospital mortality after surgery, where anaemia was defined according to the World Health Organization definition (Word document)

\section{Editor's comments}

In this issue of $B 7 S$ a couple of papers focus on bleeding and anaemia. Patient blood management (PBM) reviewed by Clevenger et al. (Br 7 Surg 2015; 102: 1325-1337) is a collection of strategies to improve blood transfusion practices that is adopted by the WHO and spreading across Europe. There is increasing evidence that implementation of PBM is associated with improved clinical outcomes, and the principles of PBM can be used to address anaemia, blood loss and transfusion in the surgical setting.

In this meta-analysis by Fowler et al. preoperative anaemia is associated with short-term mortality after surgery and an increased incidence of stroke, acute kidney injury and infection. Allogeneic red cell transfusion was unsurprisingly more common in the presence of anaemia. Although the observed preoperative anaemia is partly related to co-morbidity in the surgical patient, one cannot help wondering whether the outcome could be improved by leaning on the PBM pillars?

Primum non nocere as stated in the Hippocratic oath should be adhered to when considering anaemia and transfusion in the surgical patient, instead of a knee-jerk reaction to treat a haemoglobin level on the laboratory chart. 